\title{
Calciphylaxis presenting as digital ischemia
}

\author{
Noora Kazanji · John Falatko • Saroj Neupane • \\ Gampala Reddy
}

Received: 25 November 2014/ Accepted: 3 December 2014/Published online: 16 December 2014

(C) SIMI 2014

A 31-year-old woman with end-stage renal disease (ESRD) secondary to membranoproliferative glomerulonephritis presented with gradually worsening severe right hand pain that started during hemodialysis. Physical examination revealed livedo reticularis present on the right hand along with cyanotic digits, and a peri-ungal eschar on the third digit (Fig. 1a). Decreased right radial and ulnar pulses were present. The initial phosphorous level was $8.5 \mathrm{mg} / \mathrm{dL}$. The patient had been hyperphosphatemic for several years prior to presentation. An arterial doppler study with duplex of the right hand was negative for a thrombus but revealed diminished waveforms in the digits. A right hand X-ray study showed vascular calcifications of both the radial and ulnar arteries and soft tissue calcifications along the digits (Fig. 1b). A skeletal survey revealed extensive soft tissue, and vascular calcifications of the bilateral calves and distal common carotid arteries (Fig. 1c). She was diagnosed with

N. Kazanji $(\varangle) \cdot$ J. Falatko $\cdot$ S. Neupane

Department of Internal Medicine, Beaumont Health System,

3601 W 13 Mile Rd, Royal Oak, MI 48073, USA

e-mail: noora.kazanji@beaumont.edu

J. Falatko

e-mail: john.falatko@beaumont.edu

S. Neupane

e-mail: saroj.neupane@ beauomont.edu

G. Reddy

Department of Nephrology, Beaumont Health System,

3601 W 13 Mile Rd, Royal Oak, MI 48073, USA

e-mail: Gampala.Reddy@beaumont.edu calcific uremic arteriolopathy (CUA), and started on sodium thiosulfate during dialysis.

CUA is a rare condition of extensive microvascular calcifications that progress to livedo reticularis and nonhealing ulcers. It should be a diagnostic consideration in patients with painful, subcutaneous nodules, plaques, or necrosis. The most significant risk factor for the development of CUA is persistently raised plasma phosphate levels, as was seen in our patient. This is thought to induce the disease due to the precipitation of calcium phosphate crystals into small- and medium-sized vessels. Frequently, patients will have non-compliance with medications, a lowphosphate diet, and dialysis treatment prior to the onset of calciphylaxis. Other risk factors that follow include: increasing age, increasing length of time on dialysis therapy, dyslipidemia, presence of diabetes, corticosteroids and immunosuppression [1]. Skin biopsy is infrequently performed for diagnosis because of poor healing and risk for secondary infections [2]. X-ray studies can emphasize and suggest the correct diagnosis in the setting of chronic dialysis. Treatment is aimed at controlling underlying hyperparathyroidism with bisphosphonates, parathyroidectomy, or cinacalcet in addition to dialysis in ESRD. Sodium thiosulfate is another treatment option; it displaces calcium ions from calcium deposits to form calcium thiosulfate, which is then dialyzed or excreted by functioning kidneys [3]. 


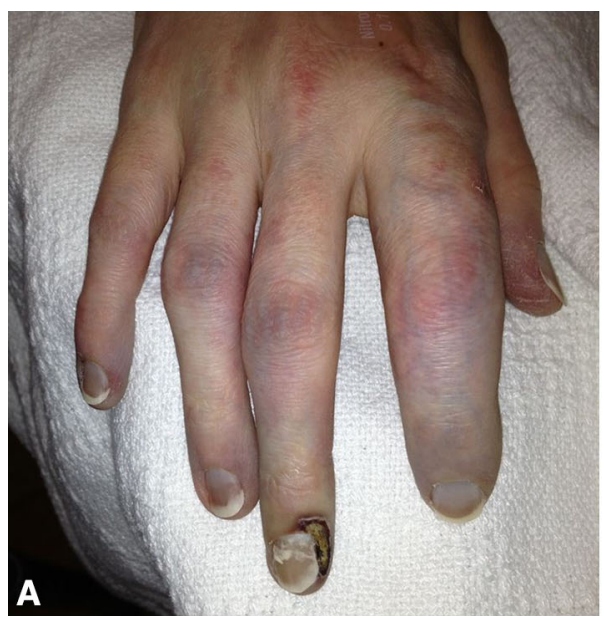

Fig. 1 a Hand photograph showing livedo reticularis, presence of digital cyanosis and a dry peri-ungal eschar of the third digit. b Vascular calcifications of the interdigital vessels (black arrow), and of the radial (white arrow) and ulnar arteries. Extensive soft tissue calcifications (asterisk) noted throughout the hand with evidence of

\section{Conflict of interest None.}

\section{References}

1. Coates T, Kirkland GS, Dymock RB et al (1998) Cutaneous necrosis from calcific uremic arteriolopathy. Am J Kidney Dis 32(3):384-391

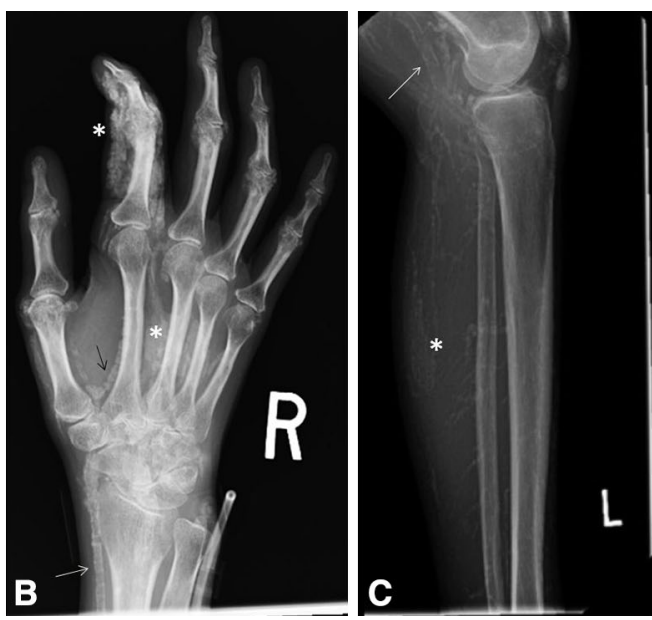

periarticular demineralization leading to swelling of the index finger with a decrease in extension, and swelling of the PIP of the middle and ring fingers. c Left tibiofibular plain X-ray study revealing soft tissue (asterisk) and vascular calcifications of the calf (white arrow)

2. Bleibel W, Hazar B, Herman R (2006) A case report comparing various radiological tests in the diagnosis of calcific uremic arteriolopathy. Am J Kidney Dis 48:659

3. Ong S, Coulson IH (2012) Diagnosis and treatment of calciphylaxis. Skinmed 10(3):166-170 